\title{
Can Lessons From Systems-Based Mastery Learning for Thoracentesis Be Translated to Hospitalists?
}

\author{
Trevor Jensen, MD, MS*, Andrew Lai, MD, MPH, Michelle Mourad, MD
}

Department of Medicine, University of California, San Francisco School of Medicine, San Francisco, California.

There has been a nationwide shift away from general internists performing bedside thoracenteses and toward referring them to pulmonology and interventional radiology services. ${ }^{1}$ Aligning with this trend, the American Board of Internal Medicine now only requires that internal medicine (IM)-trained physicians understand the indications, complications, and management of bedside procedures. ${ }^{2}$

However, thoracentesis is still considered a core competency of practicing hospitalists, the fastest growing field within general IM. ${ }^{3}$ Furthermore, evidence suggests that thoracenteses done by general internists have high patient satisfaction, reduce hospital length of stay, are more cost-effective, and are as safe as those done by consultants. ${ }^{4-6}$ It is thus important to understand the reasons for referrals to specialty services and to investigate potential interventions that increase performance of procedures by internists.

In this issue of the Journal of Hospital Medicine, Barsuk and colleagues present a prospective, singlecenter study assessing the impact of simulation-based mastery learning (SBML) on thoracentesis among a randomly selected group of IM residents. ${ }^{7}$ They studied how their program influenced simulated skills, procedural self-confidence, frequency of real-world performance, and rate and reasons for referral to consultants. The authors compared the latter outcomes to traditionally trained residents and hospitalists, finding that SBML improved skills, self-confidence, and the relative frequency of general internist-performed procedures. Low confidence and limited time were the primary reasons for referral.

To our knowledge, this is the first study to show that SBML can lead to a clinically and statistically significant change in thoracentesis referral patterns, which may have important implications for hospitalists. Given the inconsistent amount and quality of procedural training across IM residency programs, hospitalists may be increasingly ill prepared to perform

*Address for correspondence and reprint requests: Trevor Jensen, MD, University of California San Francisco School of Medicine, 533 Parnassus Avenue, U127 San Francisco, CA 94143; Telephone: 415-4767479; Fax: 415-476-4818; E-mail: trevor.jensen@ucsf.edu

Additional Supporting Information may be found in the online version of this article.

Received: July 29, 2016; Revised: August 22, 2016; Accepted: August 28, 2016

2016 Society of Hospital Medicine DOI 10.1002/jhm.2655

Published online in Wiley Online Library (Wileyonlinelibrary.com). thoracentesis and train future generations in its best practices. $^{2,8,9}$ This study demonstrates that SBML can provide trainees with essential hands-on skills development and experience that is often missing from traditional training models.

Yet, although SBML seems to affect resident referral patterns, its potential impact on practicing hospitalists is less clear. Hospitalists provide the majority of care for general medicine inpatients around the country, and in this study had a dramatically lower rate of bedside procedure performance than even traditionally trained residents $(0.7 \%$ vs $14.2 \$)$, which makes them vital to any strategy to increase bedside thoracentesis rates. ${ }^{9}$ Yet the results by Barsuk et al. suggest that the effect size of SBML on hospitalists may be much smaller than on trainees. First, the primary driver of resident practice change appeared to be increased confidence, but baseline hospitalist confidence was significantly greater than that of traditionally trained residents. Second, it is unclear what, if any, effect SBML would have on the time needed to perform a thoracentesis, which was a major factor for hospitalists referring to consult services. Lastly, given the known decrement in procedural skills over time, the durability and associated costs of longitudinal SBML training are unknown. ${ }^{10-12}$

The fact that general internist-performed thoracenteses are as safe and more cost-effective than those performed by consultants is a compelling argument to shift procedures back to the bedside. However, these cost analyses do not account for the opportunity cost for hospitalists, either in lost time spent caring for additional patients or in longer shift lengths. It is important to understand whether and how it can be feasible for general internists to perform more bedside thoracenteses so physician training and resource utilization can be optimized. Whereas confidence and time are likely limiting factors for all general internists, this study suggests that their relative importance may markedly differ between residents and hospitalists, and it is unclear how much the change in confidence resulting from SBML would affect the rates of thoracentesis by generalists beyond practice settings involving trainees. The feasibility, cost, and efficacy of SBML deserve more study in multiple clinical environments to understand its true impact. Ultimately, we suspect that only an intervention addressing procedural time demands will lead to meaningful, sustained increases in general internist-performed thoracenteses. 


\section{References}

1. Wigton RS, Alguire P. The declining number and variety of procedures done by general internists: a resurvey of members of the American College of Physicians. Ann Intern Med. 2007;146(5):355-360.

2. American Board of Internal Medicine. Internal medicine policies. Available at: http://www.abim.org/certification/policies/internal-medicinesubspecialty-policies/internal-medicine.aspx. Accessed July 18, 2016.

3. Society of Hospital Medicine. SHM core competencies. Available at: http://www.hospitalmedicine.org/Web/Education/Core_Competencies/ Web/Education/Core_Competencies.aspx. Accessed July 18, 2016.

4. Mourad M, Auerbach AD, Maselli J, Sliwka D. Patient satisfaction with a hospitalist procedure service: is bedside procedure teaching reassuring to patients? J Hosp Med. 2011;6(4):219-224.

5. Kozmic SE, Wayne DB, Feinglass J, Hohmann SF, Barsuk JH. Factors associated with inpatient thoracentesis procedure quality at university hospitals. Jt Comm J Qual Patient Saf. 2016;42(1):34-40.

6. Ault MJ, Rosen BT, Scher J, Feinglass J, Barsuk JH. Thoracentesis outcomes: a 12-year experience. Thorax. 2015;70(2):127-132.
7. Barsuk JH, Cohen ER, Williams MV, et al. The effect of simulationbased mastery learning on thoracentesis referral patterns. J Hosp Med. 2016;11(11):792-795.

8. Padgaonkar A. What we know about hospitalists. Innovative Thinking website. Available at: http://innovativesolutions.org/innovativethinking/what-we-know-about-hospitalists. Accessed July 18, 2016.

9. Wigton RS, Blank LL, Nicolas JA, Tape TG. Procedural skills training in internal medicine residencies. A survey of program directors. Ann intern Med. 1989;111(11):932-938.

10. Huang GC, Smith CC, Gordon CE, et al. Beyond the comfort zone: residents assess their comfort performing inpatient medical procedures. Am J Med. 2006;119(1):71:e17-e24.

11. Ericsson KA. Deliberate practice and the acquisition and maintenance of expert performance in medicine and related domains. Acad Med. 2004;79(10 suppl):S70-S81

12. Smith CC, Huang GC, Newman LR, et al. Simulation training and its effect on long-term resident performance in central venous catheterization. Simul Healthc. 2010;5(3):146-151. 